
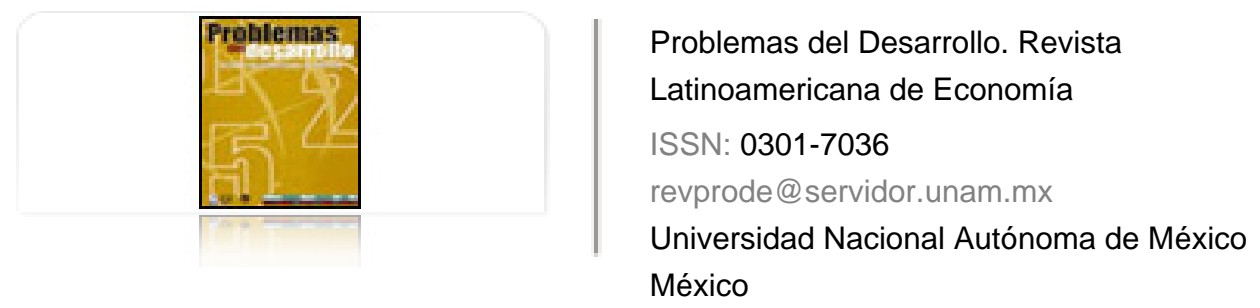

Caballero, Gonzalo

Abriendo la caja negra del Estado español: reglas, vetos, intereses y jerarquía en la formación de la política económica

Problemas del Desarrollo. Revista Latinoamericana de Economía, vol. 37, núm. 144, enero-marzo, 2006, pp. 193-219

Universidad Nacional Autónoma de México

Distrito Federal, México

Disponible en: http://www.redalyc.org/articulo.oa?id=11820097009

Cómo citar el artículo

- Número completo

- Más información del artículo

Página de la revista en redalyc.org

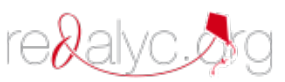

Sistema de Información Científica

Red de Revistas Científicas de América Latina, el Caribe, España y Portugal Proyecto académico sin fines de lucro, desarrollado bajo la iniciativa de acceso abierto 


\section{ABriENDO LA CAJA NEGRA DEL ESTADO ESPAÑOL: REGLAS, VETOS, INTERESES Y JERARQUÍA EN LA FORMACIÓN DE LA POLÍTICA ECONÓMICA*}

\section{Gonzalo Caballero**}

Fecha de recepción: 27 de enero de 2005. Fecha de aceptación: 11 de febrero de 2006.

\section{Resumen}

La nueva economía institucional ha incorporado las organizaciones a la agenda de investigación de la ciencia económica sobre bases teóricas renovadas, en las cuales el Estado aparece como elemento clave. Este artículo intenta abrir la caja negra del Estado español al estudiar elementos como el establecimiento del parlamentarismo y la relación entre el sistema político y los derechos de propiedad. Asimismo, indaga cómo el sistema español resuelve los trade-offs entre resoluteness-decisiveness $y$ public-private regardedness en la formación de las políticas públicas, y analiza la relación de agencia vertical mediante la cual se forma la política económica. La estructura organizativa del Estado establece, así, un marco institucional que sesga la formación de las políticas públicas.

Palabras claves: economía de las instituciones, Estado, parlamentarismo, agencia vertical, políticas públicas.

* Una versión previa fue presentada en el vi Congreso Nacional de Ciencia Política y de la Administración. Este trabajo se desarrolló en el Centro de Estudios Avanzados en Ciencias Sociales (Instituto Juan March) y en el Center for New Institutional Social Sciences y el Department of Economics (Washington University). El autor agradece la ayuda financiera de la Secretaría de Investigación de la Xunta de Galicia, así como los comentarios de tres evaluadores anónimos.

* Departamento de Fundamentos del Análisis Económico, Historia e Instituciones Económicas, Universidad de Vigo, Correos electrónicos: gcaballero@uvigo.es y gcaballerom@yahoo.com 


\section{Abstract}

The new institutional economy has incorporated into the organizations the agenda of economic research based on renewed theoretical bases, in which the State appears as a key element. This paper tries to open up the black box of the Spanish State to study such elements as the establishment of parliamentarianism and the relationship between the political system and property rights. At the same time, it investigates the Spanish system for resolving tradeoffs between resoluteness-decisiveness and public-private regard in the formation of public policies, and analyzes the relationship of vertical agency by which economic policy is formed. The State's organizational structure therefore established an institutional framework that biases the formation of public policies.

Key words: institutional economies, State, parliamentarianism, vertical agency, public policies.

\section{Résumé}

La nouvelle économie institutionnelle a incorporé les institutions dans l'agenda d'investigation des sciences économiques sur des bases théoriques rénovées, dans lesquelles l'Etat apparaît comme élément clef. Cet article essaye d'ouvrir la caisse noire de l'Etat espagnol en étudiant des éléments tels que l'établissement du parlementarisme et la relation entre le système politique et les droits de propriété. De même, il fait des recherches sur comment le système espagnol résout les trade-offs entre resoluteness-decisiveness et public-private regardedness dans la formation des politiques publiques; il analyse la relation d'agence verticale au moyen de laquelle la politique économique se forme. La structure organisatrice de l'Etat établit, de cette façon, un cadre institutionnel qui coupe en biais la formation des politiques publiques.

Mots-cléfs: economie des institutions, Etat, parlementarisme, agence verticale, politiques publiques.

\section{Resumo}

A nova economia institucional incorporou às organizações à agenda de pesquisa da ciência económica sobre bases teóricas renovadas, nas quais o Estado aparece como elemento chave. Este artigo tenta abrir a caixa preta do Estado espanhol ao estudar elementos como o estabelecimento do parlamentarismo e a relação entre o sistema político e os dereitos de propiedade. Da mesma maneira pesquisa como é que o sistema espanhol resolve os trade-offs entre resoluteness-decisiveness e public-private regardedness na formação das políticas públicas e analiza a relação de agência vertical mediante a qual forma-se a política económica. A estrutura organizativa do Estado estabelece, então, um marco institucional que entrevê a formação das políticas públicas.

Palavras chave: economia das instituções, Estado, parlamentarismo, agência vertical, políticas públicas.

\section{DeSarrollo}




\section{Introducción}

lo largo de las últimas décadas, las instituciones han regresado a la agenda de
investigación en economía sobre bases teóricas renovadas. El programa de la
Nueva Economía Institucional (NEI), edificado en la noción coaseana de costes de transacción (Coase, 1937, 1960) y en la northiana de instituciones (North, 1990a), ha constituido un sólido cuerpo teórico que destaca la importancia de estas últimas en la evolución de toda economía (Furubotn y Richter, 1998; Williamson, 2000; Caballero, 2002a; Toboso y Compés, 2003; Caballero y Kingston, 2005).

Las instituciones determinan el volumen de los costes de transacción de la economía, afectando las posibilidades del intercambio y el grado de eficiencia. En el marco institucional de la economía, el Estado resulta clave en el "primer orden de economización" de Williamson (2000). Por ello, la economía de las instituciones abarca el estudio de la organización estatal y analizar los incentivos que establece para la formación de las políticas públicas y sus efectos en las relaciones entre instituciones y economía.

El análisis del Estado ha experimentado en la ciencia económica una evolución similar a la del estudio de la organización de la empresa. ${ }^{1}$ Durante décadas, los economistas buscaban detectar fallos de mercado que la actuación pública debería corregir, pero no indagaban cómo se producía la toma de decisiones que debería dar solución a los problemas que se planteaban, suponiendo implícitamente que el gobernante era un homo-benevolente que intentaría maximizar el bienestar general. La teoría de la elección pública rompió con buena parte de esas tendencias al asumir el carácter de homo-economicus del político, y extender las nociones y enfoques de la economía neoclásica al estudio de la política. Sin embargo, este enfoque, propio del imperialismo de lo económico, presentaba ciertas deficiencias que, entre otras cosas, incluían una inadecuada conceptuación de los costes de transacción y de las instituciones en los mercados políticos (Caballero y Arias, 2003). Esta situación cambió en los últimos años gracias a los esfuerzos que, realizados desde la NEI, estudian las claves del proceso de decisión pública e intentan "abrir la caja negra" del Estado en el sentido de North (1990b) y Dixit (1996), destacando la importancia de los elementos institucionales y organizativos.

1 La corriente principal en economía la consideró durante mucho tiempo un elemento de naturaleza desconocida, cuyo interior no resultaba de interés para analizar. Se trataba de una "figura misteriosa" cuya existencia se tomaba como dada (Hahn, 1981). De este modo, hubo que esperar el impulso propiciado por Coase (1937) para que los economistas intentasen "abrir la caja negra" de la empresa, descubriendo su naturaleza como organización (Caballero, 2001).

\section{DeSarrollo}


De ese modo, la NEI constituye un instrumento útil para estudiar la estructura de gobernanza del Estado, analizando cómo las soluciones institucionales determinan los incentivos que encaran los agentes político-económicos, sesgan la elaboración de las políticas públicas y afectan la morfología de la gobernanza. ${ }^{2}$ En ese sentido, también se debe señalar la obra de Mancur Olson, la cual mantiene puntos de contacto con el enfoque de la NEI. ${ }^{3}$

El estudio de las instituciones político-económicas españolas desde estas nuevas y sólidas bases teóricas configura una agenda de investigación de largo recorrido. Muchos son los aspectos susceptibles de ser analizados, y este artículo aborda algunas de las cuestiones centrales. Lo primero que se debe señalar es que ceñimos nuestro estudio a la actual etapa democrática del Estado español, por lo cual su transición política a la democracia no es objeto de investigación de este trabajo (lo ha sido de otros). ${ }^{4}$ Una vez fijado el periodo, cabe fundamentar la selección temática del artículo sobre los determinantes institucionales de las políticas públicas en España. Se estudian algunas de las principales instituciones políticas que constituyen reglas para la gobernanza del Estado y el comportamiento de los actores políticos. Así, empezamos examinando dos cuestiones estructurales que imponen restricciones a otras elecciones políticas secundarias del gobierno democrático: la tradición legal del país (Andonova, 2002, 2003) y la institución del parlamentarismo (Moe y Caldwell, 1994). A continuación abordaremos, para el caso español, la problemática apuntada por Cox y McCubbins (1999) acerca de los determinantes institucionales de la política económica, estudiando cómo las instituciones españolas resuelven las elecciones entre capacidad de compromiso y de decisión, por un lado, y entre atención de intereses de naturaleza pública y de naturaleza privada, por otro. Este marco institucional constituye un conjunto de reglas que determina la estructura de gobernanza de la política económica, cuestión abordada en el epígrafe anterior a las conclusiones.

2 La elección de la fórmula institucional tiene consecuencias hacia todo el bloque de gobierno democrático (Moe y Caldwell, 1994). El conjunto de dicha fórmula resulta clave para determinar el grado de éxito de la delegación de la autoridad soberana del pueblo en los decisores políticos, de modo que los organismos políticos pueden constituir institutions of knowledge que resuelvan acertadamente el dilema democrático (Lupia y McCubbins, 1998). En ese sentido, a pesar de los riesgos inherentes a la delegación política, las instituciones pueden mitigar tales riesgos y favorecer una tendencia hacia la elección colectiva racional.

3 En Caballero y Arias (2003) se analizan y comparan algunos aspectos de las aportaciones de North y Olson, quienes junto a Barzel (por ejemplo, 2002) son autores de referencia en materia de economía política institucional del Estado. La obra de Olson abordó diversas cuestiones, desde tra bajos clásicos como el de 1965 o el de 1982, hasta su última aportación en 2000, en la cual se mantiene un claro enfoque institucional, aun cuando el autor se distancia de ciertas aplicaciones transaccionales.

4 El análisis de la transición política española desde un enfoque económico institucional se ha realizado en trabajos como los de Caballero (2002b y 2005b). En éstos se formula una teoría institucional del franquismo que explica el cambio institucional desde un Estado depredador a uno contractual, conforme a la teoría de North (Caballero, 2005b), y la reorientación en la tendencia de la senda de la economía española hacia un nuevo escenario de instituciones self -reinforcing, de acuerdo con la

\section{Desarrollo}




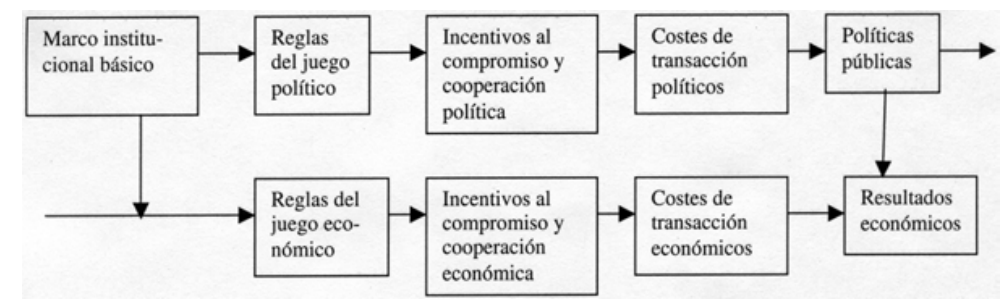

Gráfica 1. Análisis político de costes de transacción: secuencia lógica.

Así pues, este trabajo introduce el bisturí en la "caja negra" del Estado español en un ejercicio propio de economía política madisoniana (Shepsle, 1999). ${ }^{5}$ La agenda temática del artículo se centra en los siguientes aspectos: $a$ ) la relación entre el sistema de derechos de propiedad y el sistema político; $b$ ) la institución del parlamentarismo; $c$ ) la escasez de actores de veto; $d$ ) la prioridad en la atención de los intereses públicos nacionales; $e$ ) la relación vertical de agencia para la elaboración de la política económica. ${ }^{6}$

\section{Reglas politicas y derechos de propiedad}

La elección del sistema político es una "política de elección estructural" en el sentido de Moe (1990), pero también instituciones como el sistema jurídico y, particularmente, el régimen de los derechos de propiedad constituyen ejemplos de elecciones estructurales. El modelo del sistema legal se complementa con la estructura de gobierno para concretar las relaciones entre el papel del Estado y los derechos de propiedad. Las instituciones del sistema político de un país establecen las reglas que limitan a la mayoría en la posibilidad de mejorar su situación a costa de la minoría. Tales instituciones se convierten en variables claves para el sostenimiento de un Estado contractual en el sentido northiano (North y Weingast, 1989; Arias y Caballero, 2003). De ese modo, existen dos tipos de mecanismos para la defensa de los derechos económicos: los derechos políticos y los de propiedad. En ese sentido, de acuerdo con la Gráfica 1, en el marco institucional básico se establecen las reglas claves del juego político y las del económico, entre las cuales ocupan un lugar importante los derechos de propiedad.

En cuanto a las reglas políticas y los derechos de propiedad, en el programa de economía política, Andonova (2002 y 2003) estudia el equilibrio que ante intereses divergentes

teoría del cambio institucional de Avner Greif (Caballero, 2002b y 2005c). Acerca del papel de la burocracia en la transición y consolidación democrática véase Villoria (2001).

5 Este análisis no ignora la importancia que la nueva economía institucional concede a los sistemas de creencias (Denzau y North, 1994), al paso del tiempo (North, 2000) y al elemento histórico (Caballero, 2004) ni tampoco al carácter interdisciplinar que emite la ambiciosa hipótesis de "matrimonio de la teoría política y la económica" (North, 1999).

6 Evidentemente, esta selección no niega la relevancia de otras cuestiones, como la estructura institucional de la descentralización política española, que analiza Caballero (2005a). 
puede aportar la combinación, por un lado, del sistema electoral y de gobierno, y por otro, de la protección explícita de derechos de propiedad, la cual está afectada por la tradición jurídica. Según esta propuesta, el derecho civil, menos individualista y más intervencionista, se complementa con formas de gobierno más participativas y constructoras de consenso, mientras el individualista derecho común lo hace mejor con acuerdos institucionales mayoritarios. ${ }^{7}$ Desde este enfoque institucional (menos estrecho que el de un legalismo centrado únicamente en la tradición jurídica), se apunta que el grado de intervencionismo es proporcional al de representación en un gobierno democrático: cuanto más representativo sea el gobierno, tendrá mayor libertad de acción porque el interés de más grupos sociales se expresa en sus acciones y, como consecuencia, habrá menos resistencia a su intervención, pues tiene un plus de legitimidad. La configuración del sistema político importa para la protección explícita de derechos de propiedad: en general, las formas de gobierno menos representativas en países democráticos generan una protección de derechos de propiedad más explícita.

Las tradiciones del derecho civil y del común se diferencian en el grado en que usan los precedentes judiciales y el derecho estatutario. ${ }^{8}$ Sin embargo, cabe señalar que recientemente diversos autores sostienen que, en la práctica, el funcionamiento actual de esas tradiciones no resulta muy diferente, pues ambas usan el derecho consuetudinario y dan capacidad normativa a las cortes. ${ }^{9}$

Asimismo, se puede afirmar que el mismo nivel de protección de derechos de propiedad lo pueden conseguir países con diferentes tradiciones legales pero con estructuras políticas similares. Ello supone admitir que el estudio de protección de dichos derechos, centrado únicamente en las leyes, resulta estrecho. El grado de exclusión o de inclusión en el proceso de decisión colectiva es determinante del nivel de esa protección. Así pues, la caracterización de la forma básica de democracia de un país como modelo consensual o modelo mayoritario (es decir, que sesga la decisión colectiva hacia el consenso o hacia la mayoría) resulta determinante para estudiar cómo en esa economía se pueden proteger los derechos de propiedad.

En el caso español, el sistema jurídico se construye sobre la tradición legal francesa del derecho civil, supuestamente menos protectora de derechos (La Porta et al., 1998), y

$7 \quad$ En este apartado utilizamos derecho civil y derecho común para referirnos a las tradiciones jurídicas del civil law y del common law, respectivamente.

8 Las dos tradiciones legales citadas recogen diferentes herencias culturales e intelectuales. Así, el derecho común puede ser analizado, en origen, como mecanismo de protección de la propiedad privada contra la Corona (recogiendo la tradición británica iniciada en el siglo XVII). Por el contrario, los códigos comerciales de Francia y Alemania del siglo xix tenían por objeto ayudar al Estado a regular la actividad económica, tradición a la que se incorpora el caso español.

$9 \quad$ Además, en las sociedades modernas, la diferencia entre el derecho común y el civil está eclipsada por el mayor peso del legislativo como institución primaria en el proceso de creación del derecho (también en el derecho común).

\section{DeSarrollo}


asume un sistema institucional parlamentario de regla proporcional que busca propiciar el consenso en la Constitución de 1978. En un sistema como éste, los partidos no ganadores pueden defender activamente sus derechos dentro de las instituciones gubernamentales. Las minorías pueden obtener poder político porque consiguen representación (no estamos ante un "ganador que gana todo"), mientras reciben una protección de sus derechos de propiedad menos explícita. Estas formas de gobierno más representativo producen sistemas de protección menos claros que en los países de sistema mayoritario, en el cual los perdedores se quedan fuera del gobierno al menos hasta las elecciones siguientes, y en el que puede haber gran incertidumbre sobre el ganador (Andonova, 2002). Por tanto, un régimen parlamentario de regla proporcional, como el español, será más representativo de los grupos de la sociedad, por lo cual generará un legislativo menos explícitamente protector.

Por todo ello, el establecimiento de un régimen democrático en España y la decisión del sistema político de la Constitución forman una elección estructural que se combina adecuadamente con la tradición española de sistema legal. Todo ello configura parte de los fundamentos institucionales de la gobernanza democrática en España.

\section{La institución del sistema parlamentario}

Las instituciones políticas constituyen las reglas por medio de las cuales los ciudadanos determinan cómo van a establecer la gobernanza del país y cómo eligen a los representantes encargados de llevarla a cabo. El establecimiento de un régimen político democrático tiene en las elecciones el mecanismo fundamental para disciplinar a los decisores políticos, intentando evitar los abusos en la delegación del poder político y abordando las cuestiones de la "selección política" (Besley, 2005). En ese sentido, los organismos electorales pueden servir a los votantes para adquirir sustitutos útiles del conocimiento del que carecen. ${ }^{10}$ Esto se lleva a cabo cuando clarifican los intereses de los políticos, cuando establecen cargas de costes y esfuerzos a éstos, y cuando crean la amenaza de la verificación (Lupia y McCubbins, 1998). ${ }^{11}$

10 Con mayor detalle, siguiendo a Persson et al. (1997) podemos señalar cuatro funciones principales de las elecciones: a) añaden y representan las preferencias de los votantes, las cuales pueden entrar en conflicto; $b$ ) agregan información dispersa acerca de decisiones políticas concretas; $c$ ) encaran un problema de selección adversa al permitir a los ciudadanos seleccionar a los individuos que juzguen más competentes para ocupar un cargo público; d) constituyen un mecanismo para controlar el riesgo moral, haciendo a los cargos electos responsables ante los ciudadanos.

11 Los electores se reservan el derecho de retirar al político de su cargo en la próxima convocatoria electoral, de forma que la amenaza sobre el mal ejercicio de éste en su función de agente viene dada por la posibilidad de denegarle el derecho a tomar decisiones en el futuro. De ese modo, se intentan reducir las posibles "rentas del político", que vienen dadas por factores como la naturaleza coercitiva del poder o la existencia de importantes asimetrías informativas (Persson et al., 1997).

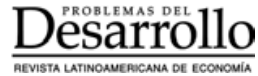


En la reciente experiencia política española, las elecciones jugaron un papel clave para la consolidación de la democracia en un escenario de estabilidad institucional en la cual no se han modificado reglas como el sistema electoral, la formación de gobiernos o las relaciones parlamentarias (Montero, 1998). Así, las elecciones permitieron ratificar la Constitución, reafirmar la legitimidad del nuevo régimen tras el golpe de Estado de 1981 y cambiar al partido en el gobierno en tres ocasiones (de UCD al PSOE en 1982; del PSOE al PP en 1996 y del PSOE al PP en 2004).

Junto al establecimiento de un régimen democrático con elecciones regulares, la Constitución de 1978 estableció un sistema parlamentario que permite al partido que obtiene la mayoría en el Congreso formar gobierno y, con ello, le proporcionará mecanismos para desarrollar su programa. El partido en el gobierno, que no está sujeto a controles fuertes, tiene autoridad total para sacar proyectos adelante, pero cuando en el futuro gobierne otro partido, ocurrirá lo mismo. En el sistema español, el ejecutivo proviene del legislativo, y ambos son controlados por el partido mayoritario (o coalición mayoritaria), reduciéndose los mecanismos de separación de poderes. El ejecutivo asume el liderazgo del partido mayoritario y con él, el del propio legislativo. La aproximación al modelo español permite corroborar que el sistema parlamentario conlleva incertidumbre política, alta dificultad de garantizar compromisos y "situación de miedo" a la actuación política del Estado (Moe y Caldwell, 1994). ${ }^{12}$

En trabajos clásicos como el de Bagehot (1867), se defiende la conveniencia de un sistema parlamentario que —al vincular legislativo y ejecutivo en un único grupo-líderpromoviese la efectividad del gobierno, y lo contraponían a la fragmentación y falta de efectividad derivada de la separación de poderes. De ese modo, el parlamentarismo ofrecía ciertas ventajas, pero también es cierto que los regímenes presidencialistas de separación de poderes tienden a ser más estables (porque el ejecutivo tiene un plazo fijo), más democráticos (el ejecutivo es elegido directamente por el pueblo) y más protectores mediante la fórmula de gobierno limitado con separación de poderes.

El sistema indirecto de designación propio de un parlamentarismo como el español, que elige al gobierno - y no directamente los electores-, puede servir adecuadamente para abordar los problemas de riesgo moral del ejecutivo, a pesar de que autores como Persson et al. (1997) tienden a destacar el déficit del parlamentarismo en su capacidad para dominar y hacer responsable al poder ejecutivo en comparación con el presidencialismo.

12 En primer lugar, el partido ganador de las elecciones estará en condiciones de formar gobierno y desarrollar su propio programa de acción; pero en las elecciones siguientes otro partido puede ganar y revertir lo aprobado anteriormente, con la consiguiente incertidumbre política. En segundo lugar, el sistema parlamentario concentra el poder en el partido gobernante, generando dificultad para asumir compromisos creíbles, en el sentido de North y Weingast (1989). En tercer lugar, la autoridad no dividida alimenta un miedo al Estado: los grupos temen la actuación política en un sistema en el cual un partido tiene el monopolio de la autoridad pública (la coerción sin retar).

\section{DeSarrollo}


En ese sentido, se ha argumentado que este último controla mejor al ejecutivo porque es elegido por voto directo. Sin embargo, también en el régimen parlamentario en España los electores votan de facto, eligiendo al presidente del gobierno, y vigilan su acción con más rigor que cuando observan la actuación del legislativo. El centro de atención en un sistema de listas cerradas y bloqueadas, como el español, se sitúa en la figura del candidato a la presidencia y no en los nombres de quienes configuran la lista electoral. Los votantes resuelven así el problema de riesgo moral del ejecutivo.

En el sistema parlamentario hay un monopolio de autoridad pública, el cual dificulta el veto. Pues bien, el modelo español adopta un sistema proporcional con regla d'Hondt para el Congreso, rompiendo la tradición española de sistemas mayoritarios. Dicha proporción produce múltiples ganadores, no es manipulada por la introducción de múltiples candidatos y favorece el "comportamiento honesto" (Andonova, 2002; Colomer, 2001). El sistema d'Hondt favorece las coaliciones y los partidos grandes.

El vigente sistema electoral español se estableció con carácter provisional para las elecciones preconstitucionales de 1977 y desde entonces se mantuvo sin ninguna modificación importante, a pesar de que en la práctica ha tenido problemas en cuestiones como la pretendida igualdad de voto y la proporcionalidad votos-escaños.

Al emanar el ejecutivo de un parlamento diverso, el gobierno está más cercano a la posición del votante mediano. Además, la regla proporcional favorece la inexistencia de mayoría absoluta de asientos en el parlamento para un partido político y, cuando no hay ganador solitario, los partidos intentarán negociar. ${ }^{13}$

\section{Actores de veto y discrecionalidad de las políticas públicas}

El dilema político fundamental de un sistema económico viene dado por el hecho de que un gobierno suficientemente fuerte para proteger los derechos de propiedad y forzar contratos, lo es también para confiscar la riqueza de sus ciudadanos (Weingast, 1995). Detrás de este dilema subyace la problemática de la credibilidad del compromiso, es decir, la capacidad del actor político de comprometerse a que la delegación política recibida no se convierta en abdicación. La divergencia entre los incentivos ex ante y los ex post y la dificultad de conseguir compromisos fiables con base en una inversión en reputación, concede relevancia a la credibilidad imperativa, que se logra mediante la fijación de reglas que impiden a los poderes públicos violar sus compromisos con carácter ex post (Shepsle, 1999).

13 Debe señalarse que con la regla proporcional las minorías relevantes pueden pasar a formar parte realmente de los gobiernos, mientras el resto de las minorías observan cómo existe menos conciencia política de sus derechos que en un sistema mayoritario. 


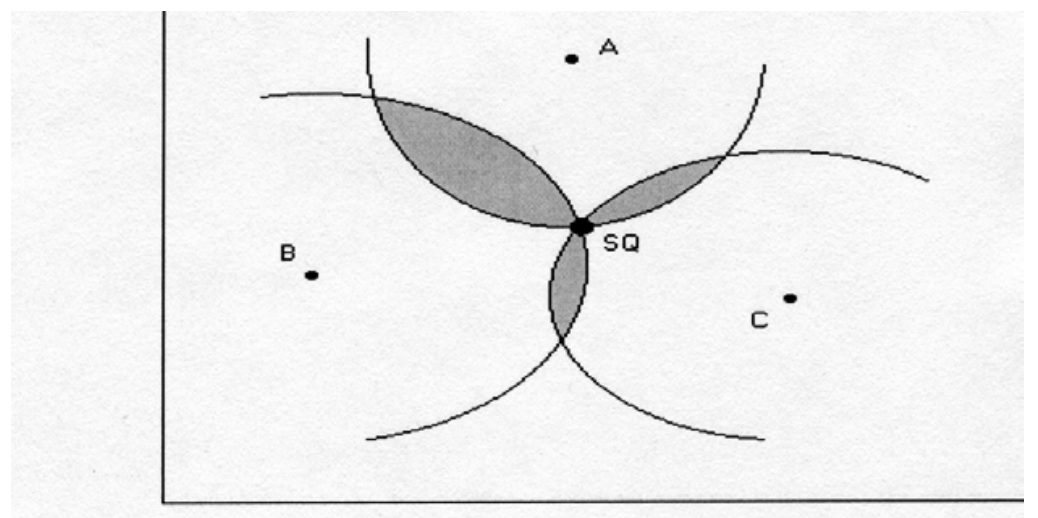

Gráfica 2. Actores de veto y statu quo en el formación de políticas.

Al definir esas reglas, debe señalarse que la presencia de actores de veto —entendidos como agentes cuyo acuerdo se requiere para tomar una decisión política (Tsebelis, 1995) — ${ }^{14}$ resuelve un trade-off entre la capacidad de los poderes públicos de llevar a cabo cambios de política (decisiveness) y la de compromiso para mantener una política dada (resoluteness) (Cox y McCubbins, 1999). ${ }^{15}$ Así, la capacidad de compromiso de las políticas va a crecer y la de decisión va a disminuir no sólo cuanto mayor sea el número de actores de veto, sino también cuando incremente la disparidad de las posiciones políticas de éstas y la cohesión interna de cada uno de ellos. Al aumentar esos tres factores, se reduce el conjunto de políticas que concitan el acuerdo suficiente para salir del statu quo, produciéndose mayor estabilidad en éstas, es decir, una reducción del potencial para introducir cambios.

Esta problemática se ilustra en la Gráfica 2. El eje de ordenadas recoge una cuestión política y el de abscisas otra; hay tres actores de veto cuyos puntos ideales de políticas son A, B, C, y se decide por mayoría. Además, cada actor es indiferente entre los puntos que están a la misma distancia de su punto ideal y prefiere los puntos más próximos a éste, por lo cual representamos curvas de indiferencia circulares ("preferencias euclideanas") que pasan por el punto de statu quo (sQ). El análisis muestra que con el sistema de mayoría las políticas que saldrían adelante son las incluidas en los tres pétalos (zona sombreada) que forman intersecciones entre dos curvas de indiferencias: ése es el conjunto ganador al statu quo. Pero además, cuando se establece el sistema de unanimidad entre actores de

14 Un actor de veto debe ser un actor con una determinada base organizacional que facilite su acción colectiva y con la capacidad de ejercitarlo de forma creíble.

15 En el continuo de posibilidades entre capacidad de compromiso y de decisión, ambos extremos suponen no gobernabilidad, bien se trate de un poder político sin capacidad alguna de compromiso (en el cual la ausencia de frenos y contrafenos hace demasiado fácil cambiar las políticas), o sin capacidad alguna de decisión discrecional (en el que la incapacidad para acordar el cambio de política puede provocar efectos perversos como la guerra institucional o el estancamiento).

\section{DeSarrollo}


veto para sacar adelante una política, el conjunto ganador al statu quo se reduce todavía más y puede llegar a ser el conjunto vacío.

El "número efectivo de actores de veto" tiene en cuenta que si los puntos de veto recaen en agentes con las mismas preferencias, la "regla de absorción" anula la efectividad de tales vetos. De ese modo, el número efectivo de éstos vendrá dado por las separaciones institucional de poderes (que determina los posibles puntos) y por la de propósito (que define la diversidad de preferencias de los actores que controlan dichos puntos). ${ }^{16}$

Entre las técnicas de separación de poderes, las tres posibilidades clásicas que dificultan la acción son el presidencialismo, el bicameralismo y el federalismo. A ellas cabe añadir la judicatura y el ejército. Tal como ha mostrado Weingast (1993, 1995), se abren cauces para limitar el poder del gobierno ("atar la manos al partido"), es decir, las instituciones políticas pueden comprometer de forma creíble al Estado en el respeto a los derechos políticos y económicos, favoreciendo los mercados prósperos.

El análisis de esas cinco variables para el caso español (separación de poderes, bicameralismo, federalismo, judicatura y ejército) constata que el marco institucional del país reduce la posible existencia de actores de veto:

a) El modelo político español establece un sistema parlamentario en el cual las cortes designan al presidente del gobierno, de forma que las preferencias de la mayoría parlamentaria se plasman en el ejecutivo. Presidente y parlamento coinciden en preferencias, de modo que éste no desarrolla de facto la figura de "actor de veto institucional". No obstante, las reglas políticas dejan espacio para la presencia de "actores de veto partidarios" en el caso de mayorías minoritarias, como es éste de las experiencias gubernamentales 1977-1982 y 1993-2000, en el cual los partidos nacionalistas negociaron acuerdos programáticos a cambio de su capacidad de veto. La legislatura abierta por las elecciones del 2004 también expresa una situación de ese tipo.

b) El bicameralismo del Parlamento español encubre una situación de desequilibrio en la que el Congreso tiene primacía sobre el Senado y en la que el sistema electoral convierte al Senado en actor de veto inefectivo (Caballero, 2005a). De ese modo, el bicameralismo no ha introducido actores de veto relevantes en la formación de las políticas públicas del país.

c) El diseño constitucional español, a pesar de haber facilitado un alto grado de descentralización, no responde a los esquemas estándares del federalismo (Bayona, 2001) y la

16 Un gobierno dividido es aquel en el cual no hay un único grupo político que controle todos los poderes separados, y cuando, además, estemos ante un Estado en cuya estructura hay un número excesivo de vetos, los gobiernos pueden tener problemas como la guerra institucional, el unilateralismo, el estancamiento, las políticas distributivas favorecedoras de intereses particulares o la tendencia hacia mayores déficit presupuestarios.

\section{DeSarrollo}


especial configuración del Estado de las Autonomías establece un sistema peculiar, abierto y complejo, que reduce las capacidades de veto del modelo federal en sentido estricto (Caballero, 2005a).

d) La judicatura no ha vetado habitualmente la formación de las políticas públicas. En este ámbito, debe analizarse el papel del Tribunal Constitucional. El derecho de propuesta de sus integrantes recae en los agentes políticos (las cortes, el ejecutivo y el Consejo General del Poder Judicial, designado a su vez por éstas), de los cuales se deriva mayor proximidad de preferencias entre políticos y Tribunal Constitucional que si los miembros de éste optasen por la carrera judicial.

e) El ejército actuó en España, durante la transición a la democracia, como un auténtico contrapoder que limitaba el conjunto de políticas viables, llegando a cuestionar al propio poder político, tal como se vio en el intento golpista de 1981. Con la llegada del gobierno socialista en 1982, se avanzó en la reforma del ejército, para acabar convirtiéndolo en parte integrante del sistema democrático, abandonando su función de actor de veto.

La escasez de dichos actores en la estructura de gobernanza del Estado español sitúa al país en un escenario lejano a aquellos en los que tener un amplio número crea un "escenario de indecisión, irresolución o balcanización" (Cox y McCubbins, 1999). En ese contexto, resulta fácil sacar adelante los proyectos políticos, incrementándose el riesgo por la falta de garantía en la estabilidad de los cambios efectuados.

En este caso, los poderes públicos españoles se ven en la necesidad de garantizar sus compromisos mediante otros mecanismos, de entre los cuales Moe y Caldwell (1994) señalan la búsqueda de reputación y normas de conducta en situaciones modelizadas como juegos repetidos, establecimiento de agencias y programas cuya posterior intervención generaría fuerte reacción política, y la cooptación (acuerdos con distintos sectores). De ese modo, el proceso de incorporación española a la Unión Europea constituye también un mecanismo institucional que refuerza la capacidad de compromiso del Estado, al evidenciarse que el coste de decisiones que incumpliesen ciertos compromisos sería demasiado alto.

\section{El sistema de partidos y la atención de intereses públicos}

El sistema parlamentario español otorga a las elecciones del Congreso de los Diputados el papel central. Éstas se desarrollan con un sistema caracterizado por: a) el principio constitucional de representación proporcional y la fórmula d'Hondt; $b$ ) una Cámara con 350 diputados, elegidos en 53 distritos electorales que corresponden a las provincias; $c$ ) la asignación de, al menos, dos escaños por distrito (Ceuta y Melilla disponen de un diputado 
cada una) y la distribución de escaños adicionales de acuerdo con el tamaño de la población; $d$ ) un umbral de 3\% mínimo en el distrito para obtener representación; ${ }^{17} e$ ) listas cerradas y bloqueadas (Montero, 1998).

Un aspecto relevante en economía política es si las reglas electorales convierten en protagonista al candidato individual o al partido político, pues éstas son clave a la hora de determinar hasta qué punto los políticos individuales pueden crear sus propias bases de poder electoral. Los marcos institucionales que incentivan a éstos a cultivar un voto personal conllevan que los legisladores en busca del voto provean de bienes privados o públicos locales a su electorado, y de servicios particulares a grupos de interés especiales. En ese escenario, la formación de las políticas públicas dependerá de muchos actores con intereses específicos, por lo cual se constituirán mayorías por medio de la concesión de beneficios especializados para múltiples minorías. Así, los costes de transacción tenderán a ser mayores, con partidos débiles y poca oferta de bienes colectivos.

El grado de intensidad con el cual los políticos cultivan el voto personal es relevante. Cuando esta intensidad es elevada se favorece: $a$ ) la cesión de las decisiones políticas a las comisiones, lejos de los partidos y líderes gubernamentales; $b$ ) cohesión menor en el seno de los partidos; c) mayor pluralismo en la negociación con los grupos de interés; $d$ ) corrupción estructural, y e) parálisis estructural para generar bienes públicos. De ese modo, las políticas atenderán demandas estrechas y especiales, propias de intereses particulares, mediante rentas fiscales (fiscal pork, pork embraces rents) que se convierten en "bocados que muerden" la actuación del Estado (Cox y McCubbins, 1999).${ }^{18}$ Esta privatización de políticas públicas tenderá a ser mayor cuando existan separaciones constitucional de poderes y electoral de propósito.

En el caso español, el sistema político y electoral concede protagonismo a los partidos políticos frente a los congresistas individuales. Las reglas constituyen un sesgo institucional que incentiva la jerarquía partidaria entre diputados y que tiende a dotar al país de la capacidad para generar políticas públicas de interés nacional (pues el partido político es un maximizador de votos que agrega un amplio conjunto de preferencias individuales). Sin embargo, tales instituciones, al no potenciar la figura del "diputado de circunscripción", implican un sesgo de descuido hacia la provisión de bienes públicos regionales o locales. ${ }^{19}$

17 Esta barrera distorsiona muy poco la proporcionalidad y sólo podría tener algún efecto en las grandes provincias, como Madrid o Barcelona.

18 En el análisis de Cox y McCubbins (1999) se señala que cuando hay un amplio número efectivo de actores de veto, la política es distributiva en intención, al satisfacer intereses privados particulares individuales, en vez de buscar la provisión de bienes públicos y la eficiencia asignativa.

19 Esta situación - que puede generar un sentir ciudadano de distanciamiento hacia la actividad política - intenta ser compensada con el proceso de descentralización política, que crea instituciones más cercanas al ciudadano y que permite ofertar de forma más sencilla bienes para territorios concretos (Caballero, 2005a).

\section{DeSarrollo}


Los diputados individuales tienen escasa libertad y son los líderes del grupo parlamentario quienes consiguen el control $\mathrm{y}$, aun cuando formalmente sean elegidos por dicho grupo, son de facto designados por la dirección del partido político, de la cual dependerá la posibilidad de reelección.

El ejecutivo sale del legislativo y ambos son controlados por el partido mayoritario. El presidente es el líder del ejecutivo y del partido mayoritario y, por tanto, del propio legislativo; de ese modo, consigue sacar adelante lo que se propone.

Los votantes, incapaces de procesar toda la información política para tomar una decisión racional, observan ciertas señales que le ayudan a elegir y, en un sistema proporcional con listas cerradas como el español, el partido político constituye una pista decisiva para orientar el voto de cada ciudadano. El nombre de marca del partido aporta una señal clave en el mercado del voto y la reputación es un bien público para todos los legisladores, de ahí se deriva que cada uno de ellos pueda actuar como un gorrón ante el problema de la acción colectiva, y será necesaria una autoridad en la jerarquía partidaria que impida tales aprovechamientos y coordine la actuación del partido.

En un sistema parlamentario, los objetivos del ejecutivo son análogos a los que en un sistema presidencial busca el presidente: ambos prestan atención a un electorado amplio, aglutinando diversos problemas e intereses, con la diferencia de que el partido mayoritario en el sistema parlamentario tiene una autoridad sin los frenos que existen en un sistema de separación de poderes. De ese modo, se resuelve el dilema de la política económica entre la atención de intereses públicos y los de naturaleza privada (Cox y McCubbins, 1999): Cuanto menor sea el número de vetos, menor será la atención de intereses privados por parte de los poderes públicos, incentivando la provisión de bienes públicos, la eficiencia asignativa y el bienestar general.

A la hora de estudiar cómo actores con diferentes problemas acaban controlando vetos separados dentro del proceso legislativo, la variable central es el sistema de partidos, fundamentalmente en lo que se refiere a su grado de concentración. Allí donde el sistema sea representativo y con distritos amplios, el sistema será débil (pocos incentivos electorales a coaligarse), mientras que donde es mayoritario y con distritos pequeños, el sistema será fuerte (altos incentivos a la coalición electoral). Cada sistema determina el número de partidos, y cuanto mayor sea éste, de igual manera serán los costes de transacción y las posibilidades de estancamiento. El número de partidos políticos viables vendrá afectado por las economías de escala existentes. Éstas ocurren cuando una alianza electoral produce mayor número de escaños que si los partidos se presentan por separado (Cox y McCubbins, 1999).

En España, el tamaño pequeño del Congreso y el amplio número de distritos electorales hace que la magnitud media de cada uno de éstos sea muy reducida (6.73 escaños por distrito), en un nivel muy cercano al mínimo aceptado para lo que se considera un sistema

\section{DeSarrollo}


ABRIENDO LA CAJA NEGRA DEL ESTADO ESPAÑOL

Cuadro 1

Magnitud de distritos electorales para la elección del Congreso de los Diputados

\begin{tabular}{lccc}
\hline Magnitud del distrito & Número de distritos & Número de escaños & Porcentaje del total de escaños \\
\hline Entre 1-6 escaños & 34 & 140 & 40.0 \\
Entre 7-8 & 7 & 50 & 14.2 \\
Entre 9-16 & 9 & 95 & 27.1 \\
Más de 16 & 2 & 65 & 18.5 \\
\hline Total & 52 & 350 & 100 \\
\hline
\end{tabular}

Fuente: medidas por Vallés y Bosch (1997) para 1996.

proporcional (sólo Irlanda tiene distritos menores que España en Europa) (véase Cuadro 1). Estas reglas del juego político producen un sesgo mayoritario significativo en los distritos pequeños, mientras que en los más amplios respetan adecuadamente la proporcionalidad (Montero, 1998). ${ }^{20}$

Así, este sistema electoral de circunscripciones con pocos escaños en juego afecta al sistema de partidos, reduciendo mecánicamente su número con representación parlamentaria, como resultado de la escasa proporcionalidad en esos distritos pequeños. De ese modo, el número efectivo de partidos parlamentarios fue inferior al de partidos electorales, en una cuantía superior a la existente para cualquier otro país europeo (Vallés y Bosch, 1997; Montero, 1998). Asimismo, el sistema electoral español constituye un marco institucional que favorece un bajo nivel de fragmentación y una desproporcionalidad considerable que, a su vez, afecta al sistema de partidos (Montero, 1998). ${ }^{21}$

El bajo nivel de fragmentación política se manifiesta en que los dos principales partidos políticos consiguen en todas las consultas más de $80 \%$ de los escaños de la Cámara, y el principal efecto mecánico del sistema electoral viene dado por la citada brecha entre el número de partidos electorales y el de parlamentarios. ${ }^{22}$

Este sistema convierte en protagonistas a los dos partidos principales, los cuales en todas las consultas electorales han tenido sobrerrepresentación (Cuadro 3); además, hacen

20 La falta de proporcionalidad se manifiesta en que los dos partidos principales tienen más escaños que votos, mientras que los partidos pequeños, con electorado muy diseminado, son los más perjudicados. El índice de desproporcionalidad se incrementa sistemáticamente cuanto menor sea es tamaño de los distritos electorales.

21 Sin embargo, puede concluirse el carácter globalmente beneficioso del sistema español en el proceso de transición y consolidación democrática, ya que no fragmentó demasiado el mapa partidista, reflejó la orientación mayoritariamente moderada del electorado y permitió que estuvieran re presentadas las distintas posiciones en las vertientes ideológica, socioeconómica y regional (Vallés y Bosch, 1997).

22 Esta situación se debe al tamaño de los distritos electorales y no sólo a la utilización de la variante d'Hondt de la fórmula de la media mayor. Todo ello genera que algunos autores, como Vallés y Bosch (1997), prefieran referirse al sistema español como "distributivo", conscientes de que su aplicación no garantiza la proporcionalidad. 
Cuadro 2

Número de escaños obtenidos: elecciones al Congreso, 1977-2004

\begin{tabular}{lrrrrrrrrr}
\hline Partidos & 1977 & 1979 & 1982 & 1986 & 1989 & 1993 & 1996 & 2000 & 2004 \\
\hline PCE/IU-IC & 20 & 23 & 3 & 7 & 17 & 18 & 21 & 8 & 5 \\
PSOE & 118 & 121 & 202 & 184 & 175 & 159 & 141 & 125 & 164 \\
UCD & 165 & 168 & 11 & - & - & - & - & - & - \\
CDS & - & - & 2 & 19 & 14 & - & - & - & - \\
AP/CD/PP & 16 & 9 & 107 & 105 & 107 & 141 & 156 & 183 & 148 \\
CIU & 11 & 8 & 12 & 18 & 18 & 17 & 16 & 15 & 10 \\
PNV & 8 & 7 & 8 & 6 & 5 & 5 & 5 & 7 & 7 \\
ERC & - & - & - & - & - & 1 & 1 & 1 & 8 \\
Otros & 12 & 14 & 5 & 11 & 14 & 9 & 10 & 11 & 8 \\
\hline Total & 350 & 350 & 350 & 350 & 350 & 350 & 350 & 350 & 350 \\
\hline
\end{tabular}

Fuente: elaborado a partir de datos del Congreso de los Diputados.

Cuadro 3

Diferencias en la proporción de votos y escaños en elecciones generales, 1977-2004

\begin{tabular}{lrrrrrrrrr}
\hline & 1977 & 1979 & 1982 & 1986 & 1989 & 1993 & 1996 & 2000 & 2004 \\
\hline PCE/IU & -3.6 & -4.2 & -2.4 & -2.7 & -4.3 & -4.5 & -4.6 & -3.2 & -3.5 \\
PSOE & +4.4 & +4.1 & +10.4 & +8.5 & +10.4 & +6.0 & +2.7 & +1 & +4.2 \\
CDS & - & - & -2.2 & -3.8 & -3.9 & - & - & - & - \\
UCD & +12.9 & +12.9 & -3.1 & - & - & - & - & - & - \\
AP/PP & -3.8 & -3.5 & +4.7 & +3.9 & +4.8 & +5.5 & +5.7 & +7 & +4.6 \\
CIU & -0.6 & -0.5 & -0.2 & +0.1 & +0.1 & 0 & 0 & 0 & -0.4 \\
PNV & +0.6 & +0.4 & +0.5 & +0.2 & +0.2 & +0.2 & +0.1 & +0.4 & +0.4 \\
ERC & - & - & - & - & - & - & -0.4 & -0.6 & -0.3 \\
\hline
\end{tabular}

Fuente: elaboración propia a partir de Montero (1998). El signo positivo significa sobrerrepresentación; el negativo infrarrepresentación.

un llamamiento al voto útil, buscando que la dimensión psicológica del sistema refuerce los efectos mecánicos del mismo. ${ }^{23}$

El sistema electoral español se convierte en una regla de juego formal que afecta la representación de los intereses económicos de los votantes y sectores, primando la sobrerrepresentación de los partidos más votados, infrarrepresentando a los partidos minoritarios de ámbito nacional y dando un trato más proporcional a los principales partidos del ámbito no estatal. ${ }^{24}$

23 Dos rasgos determinan el nivel de votación estratégica en un sistema electoral dado: el principio de asignación de escaños (a partir de los votos) y el tamaño de los distritos (Cox y McCubbins, 1999).

24 La naturaleza de estos partidos viene dada por el status político que consiguen en su comunidad autónoma, y es a éste al cual conceden mayor relevancia, decidiendo la actuación de sus grupos parlamentarios en el Congreso de los Diputados en consonancia con tales objetivos políticos autonómicos. De ese modo, algunos intereses regionales de las nacionalidades históricas y también de otras comunidades autónomas, consiguen representación en los mercados legislativos estatales.

\section{Desarrollo}


España constituye un caso de "partidos volátiles y votantes estables", el cual expresa que se afecta más el apoyo electoral por el cambio en las percepciones sobre los partidos que por las preferencias de los votantes (Montero, 1998). Por otra parte, la configuración bipolar del sistema de partidos establece una lógica centrípeta en la competencia electoral por obtener el voto del electorado de centro. ${ }^{25}$

Al estudiar cómo la elaboración de las políticas públicas incorpora la atención de intereses de distintos sectores económicos, resulta conveniente analizar la articulación de dichos intereses en el caso español. Entre las funciones principales de los partidos políticos no está actuar como correa de transmisión entre asociaciones que defienden intereses particulares concretos y el gobierno. Esto debe entenderse en un contexto de bajo asociacionismo en España (Heywood, 1998). Juan Linz (1988) ha argumentado que la articulación de los grupos de presión requiere lapsos prolongados de estabilidad política, lo cual permite consolidar sus organizaciones y legitimar sus actividades (Molins y Casademunt, 1998). En el periodo constituyente se concedió poca atención a cómo estructurar las tareas de lobby, y las actividades y relaciones entre grupos de presión y gobiernos no fueron reguladas específicamente; tampoco con posterioridad. La necesaria estabilidad política llegó a partir de 1978, en un escenario en el cual se dio cabida a la participación de agentes sociales representantes de empresarios y trabajadores.

Pero la articulación de intereses incorpora también la defensa de otros más particulares, para cuya consecución habrá que analizar los medios de interlocución con las administraciones públicas y sus posibilidades de trasladar dichos intereses a la esfera de decisión del gobierno. ${ }^{26}$

Aun cuando ciertos grupos de interés pequeños o regionales puedan capturar a algún diputado de un distrito, este poder no será relevante porque el diputado tiene incentivos para seguir las instrucciones de su líder (quien forma las listas electorales y, con ello, la posibilidad de reelección); éste intentará realizar una oferta de política económica que permita maximizar el número de votos y, así, las posibilidades de permanencia en el poder. La actividad política del presidente del gobierno no resulta capturable para los grupos de interés pequeños; solamente los grandes podrían ejercer fuerte influjo, e incluso control. ${ }^{27}$

25 Esta situación es especialmente relevante en la medida en que a la hora de explicar la estabilidad en el respaldo electoral a los distintos partidos, elementos como la identificación partidaria, las vinculaciones del voto por distintas organizaciones o los rasgos sociales (económicos, religiosos, regionales), resultan poco clarificadores, mientras el factor ideológico, asociado al debate derecha izquierda, sí consigue aclarar la dinámica electoral (Montero, 1998).

26 En la medida en que tales medios no estén adecuadamente regulados, se deja un vacío legal que en la práctica será cubierto por relaciones informales que no siguen procedimiento alguno y que ponen en contacto a los representantes del gobierno con los grupos de presión.

27 Entre los grupos de presión más pujantes en la reciente experiencia española se pueden señalar grupos sectoriales, como las organizaciones agrícolas o las asociaciones profesionales, y grupos causales, que incluyen a organizaciones como la Iglesia o aquellas defensoras del medio ambiente (Molins y Casademunt, 1998). Sin duda, una mención especial requiere el poder de los grupos 


\section{Jerarquía, agencia vertical, costes de transacción y delegación económica}

Al estudiar las instituciones en las cuales se configura la elección pública, las constituciones son contratos incompletos que dejan espacios para el abuso del poder, por lo cual resulta clave estudiar desde un enfoque positivo la gobernanza de la relación de agencia vertical para la formación de la política económica, en la que intentan actuar múltiples principales (Dixit, 1996). Desde esta perspectiva, el marco teórico de la economía política constitucional resulta insuficiente, por considerar que la Constitución lo determina todo, mientras la NEI constituye un enfoque menos estrecho, de carácter multidisciplinario, tal como se desarrolla en Caballero y Arias (2003). Junto a las inercias y las reglas institucionales que vienen dadas por la senda histórica de una sociedad, la NEI incorpora en su agenda de investigación los problemas de gobernanza, aplicando también los enfoques positivos de agencia (Furubotn y Richter, 1998; Williamson, 2000). ${ }^{28}$

La Constitución española buscaba lograr estabilidad política, por lo que a la opción parlamentaria se le sumaron severos correctivos al sistema proporcional, un sistema de listas cerradas y bloqueadas que protegiese a los líderes existentes, y la viabilidad de mociones de censura sólo si eran constructivas (Colomer, 1998). En la relación de agencia múltiple-vertical que representa el ejercicio de la política, la ciudadanía vota una lista con los parlamentarios de un partido político, y éstos designan al presidente del gobierno, quien nombra a los ministros y decide el número y las responsabilidades de cada uno de ellos. De ese modo, el ejecutivo emerge del legislativo y ambos son controlados por el partido mayoritario. La experiencia democrática española ha evidenciado, además, un carácter presidencialista del sistema, al coincidir la figura del presidente del gobierno con la de líder de partido mayoritario. ${ }^{29}$

Los parlamentarios intentan maximizar su permanencia en las cortes y, con un sistema de listas cerradas y bloqueadas, buscarán llevar a cabo conductas acordes con las instrucciones de la dirección del partido, pues es ésta la que decide las listas electorales: están más incentivados a seguir las preferencias del partido (y, en particular, del propio líder) que a las de sus electores directos (dejan que sea el partido el que capte las preferencias de todo

de comunicación, que en la práctica establecen coaliciones de intereses con determinados partidos, de modo que consiguen un trato favorable del poder político a cambio de favorecer al partido en cuestión.

28 Estos enfoques de la NEI asumen originalmente el individualismo metodológico, lo cual resulta claro en los análisis de agencia, distanciándose de la propuesta holista del viejo institucionalismo americano de autores como Thorstein Veblen. Sin embargo, dentro de la NEI existen propuestas que desbordan ese tipo de individualismo; tal es el caso del institucional. En Caballero (2004) se desarrollan esas cuestiones metodológicas.

29 Mientras fracasaban los intentos de bicefalia que diferenciaban al líder del partido del candidato a la presidencia, como la que existió en el partido socialista entre 1998 y 1999.

\section{DeSarrollo}




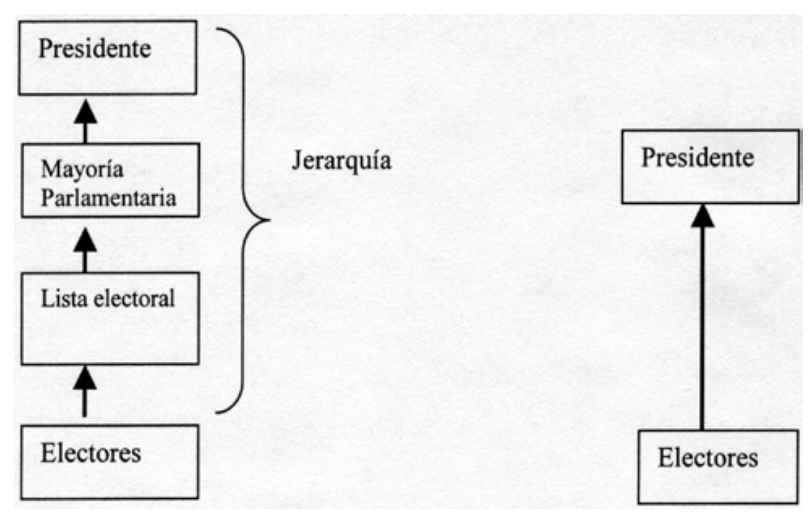

Gráfica 3. Relación de agencia vertical: la organización jerárquica.

el electorado y decida cuáles satisfacer). Por su parte, el presidente es autónomo y líder, sin ser controlado por los diputados (problema de acción colectiva).

La relación de agencia vertical de la delegación política se acaba estructurando en una jerarquía cuya cabeza es ocupada por el presidente del gobierno, convirtiendo la acción política en un sistema top-down que aborda la economización de costes de transacción. Así, la eficiencia del sistema va a depender de la capacidad del presidente para aglutinar intereses distintos y organizar la consecución de los mismos mediante la relación ejecutivopartido político-legislativo.

El sistema español es de partidos con fuerte tendencia presidencial. Las reglas políticas de la economía española dotan de gran poder a los partidos y a los líderes de éstos. Este poder se concentra especialmente en la figura del presidente del gobierno, existiendo una dificultad para garantizar el compromiso como fruto del monopolio de autoridad pública. La posibilidad de un atraco político, en el sentido de Epstein y O’Halloran (1999), está presente en cada una de las relaciones de agencia existentes.

El presidente del gobierno y líder del partido mayoritario se convierte en la cabeza de un liderazgo que, tras analizar las demandas de políticas públicas, determina la oferta política. ${ }^{30}$ El primero dirige el gobierno e impone su decisión en casos de desacuerdos entre miembros del ejecutivo. ${ }^{31}$ Además, corresponde al jefe del ejecutivo la decisión del fabricar o comprar las políticas públicas, especificando la legislación en el parlamento por

30 Este liderazgo y poder del ejecutivo se ve limitado por factores estructurales (tales como el proceso de cesión de poderes hacia organismos supranacionales, tipo Unión Europea, como hacia otros nacionales como las comunidades autónomas) y por factores contingentes (sea la existencia de mayoría absoluta en el parlamento, el grado de unidad del partido o las capacidades personales de cada miembro del ejecutivo) (Heywood, 1998).

31 Piénsese, por ejemplo, que los poderes ejecutivos del presidente se ven reforzados por sus potestades en materia de promover o dificultar la actividad legislativa, incluyendo elementos como la devolución legislativa o la capacidad de dictar decretos con rango de ley. 
medio del grupo parlamentario del partido mayoritario o ejerciendo desde el ejecutivo ciertas atribuciones legislativas con mayor peso en la burocracia. En la asignación de tales tareas, el presidente intentará minimizar los costes de transacción de la elaboración de las políticas públicas, de forma análoga al problema planteado a la teoría económica por la naturaleza de la empresa (Coase, Williamson). El análisis de Epstein y O'Halloran (1999) analiza en un sistema político de separación de poderes que, mientras la formación de leyes vía parlamentaria incurre en costes internos de transacción entre congresistas en comités, el coste de delegar en el ejecutivo-burocracia presenta el "riesgo del atraco". Es decir, el propio marco institucional parlamentario con sistema proporcional corregido convierte a la gobernanza política en una jerarquía en la cual el líder ejerce una autoridad sobre el proceso, generándose un escenario de colusión entre ejecutivo y grupo mayoritario parlamentario a las órdenes del presidente. La economía política de las instituciones españolas determinan, así, un equilibrio de autocumplimiento.

El presidente encabeza un ejecutivo fuerte al cual controla, recibiendo el poder constitucional de monopolizar las decisiones más importantes de la política nacional y de organización básica del gobierno. ${ }^{32}$ De ese modo, el estado español se caracteriza por un alto grado de concentración de poder dominado por el presidente del gobierno y un amplio margen de maniobra para las elites políticas del partido en el gobierno. Esta caracterización se desvincula de las argumentaciones que enfatizan al modelo de organización política española como neocorporatista. En ese sentido, los pactos en España han sido utilizados por el ejecutivo para obtener legitimación para determinadas políticas que resultaban impopulares o de aplicación costosa, pero en ningún caso esta actuación contractual supone una dejación de poder por parte del ejecutivo. Éste utiliza los pactos para que salgan adelante decisiones que desea, pero no los admite para que las partes contratantes puedan pactar acuerdos contrarios a la voluntad política del gobierno y su presidente y, por ello, podemos afirmar la no difusión del poder en España. La experiencia española se caracteriza más por la concentración del poder que por el peso de la concertación social (Heywood, 1998).

No obstante, el alto nivel de concentración de poder no supone una negación del mercado como mecanismo de asignación. La confrontación no fue mercado contra Estado, sino que la actuación política del Estado español tendió a reforzar el protagonismo de los mercados en función de una estructura de reglas políticas que incentivaba al actor político en la búsqueda de los intereses del electorado.

La estructura y distribución de recursos de poder en España se aproxima a la de Gran Bretaña, donde el gobierno electo también tiene amplia autonomía para formar políticas. En

32 Esos amplios poderes del ejecutivo incluyen atribuciones legislativas. Piénsese que incorporan la posibilidad de promulgar decretos ley, la posesión del monopolio de inicio de cierto tipo de legislación (como los presupuestos generales), la ejecución del presupuesto y la capacidad de nombrar al gobierno y otros cargos.

\section{Dêsarreriollo}


ABRIENDO LA CAJA NEGRA DEL ESTADO ESPAÑOL

Cuadro 4

Gobiernos y presidentes en España en el último cuarto del siglo $\mathrm{xx}$

\begin{tabular}{lcccc}
\hline Gobierno & Investidura & $\begin{array}{c}\text { Fecha de } \\
\text { dimisión }\end{array}$ & $\begin{array}{c}\text { Composición } \\
\text { del } \text { gobierno }\end{array}$ & $\begin{array}{c}\text { Mayoría } \\
\text { parlamentaria }\end{array}$ \\
\hline Suárez I & $17 / 06 / 1977$ & $02 / 03 / 1979$ & UCD & Simple \\
Suárez II & $04 / 04 / 1979$ & $29 / 01 / 1981$ & UCD & Simple \\
Calvo-Sotelo & $25 / 02 / 1981$ & $29 / 19 / 1982$ & UCD & Simple \\
González I & $01 / 12 / 1982$ & $23 / 06 / 1986$ & PSOE & Absoluta \\
González II & $23 / 07 / 1986$ & $30 / 10 / 1989$ & PSOE & Absoluta \\
González III & $05 / 12 / 1989$ & $07 / 06 / 1993$ & PSOE & Absoluta \\
González IV & $10 / 06 / 1993$ & $04 / 03 / 1996$ & PSOE & Simple \\
Aznar I & $05 / 05 / 1996$ & $18 / 01 / 2000$ & PP & Simple \\
Aznar II & $26 / 04 / 2000$ & $19 / 01 / 2004$ & PP & Absoluta \\
Rodríguez Zapatero & $15 / 04 / 2004$ & - & PSOE & Simple \\
\hline
\end{tabular}

Fuente: elaboración propia a partir de Reniu (2001).

cuanto a la estabilidad política, puede señalarse que desde el establecimiento de la democracia hasta 2000 existieron en España veintisiete ciclos políticos en el sentido de Sáez (2000).

El alto poder del jefe del ejecutivo se reduce cuando su partido no posee mayoría parlamentaria absoluta. Cuando la primera fuerza política no consigue alcanzarla, entonces se ponen en marcha los procesos de formación de coaliciones entre partidos con representación parlamentaria para conseguir la investidura del ejecutivo y, posteriormente, respaldar las tareas del gobierno.

La experiencia española revela que en esas circunstancias se forman gobiernos minoritarios monocolores de la principal fuerza política, sin que se haya producido hasta el momento un gobierno de coalición (de hecho, el caso español es el único en Europa continental en el que no hay experiencias de gobiernos de coalición). ${ }^{33}$ Dadas las instituciones del sistema español, se establece un sistema de incentivos en los decisores políticos que convierte en racional la formación de esos gobiernos minoritarios, tal como evidencian las experiencias del gobierno socialista formado en 1993, del popular de $1996 \mathrm{y} \mathrm{del}$ socialista de 2004. Para una adecuada comprensión de este fenómeno, resulta necesario analizarlo desde una perspectiva que incorpore la multidimensionalidad de los objetivos de los representantes políticos: los diversos partidos de la coalición encuentran más beneficioso mantenerse fuera del gobierno que formar un ejecutivo multipartidista (Reniu, 2001). ${ }^{34}$ Para ello, hay que tener en cuenta la existencia de problemas informacionales y

33 Este rasgo del sistema español debe explicarse en función del marco institucional que rige los procedimientos electorales y la propia configuración gubernativa. Las instituciones son, de nuevo, la clave para comprender los casos de gobierno minoritario en los cuales el presidente se ve supeditado a los procesos de negociación con partidos del ámbito regional.

34 Esta naturaleza multidimensional permite analizar a los partidos en su condición de maximizadores de cuatro elementos distintos: cargos, votos, políticas y cohesión interna, asociados respectivamente a las arenas ministerial, electoral, parlamentaria e intrapartidista (Reniu, 2001). 
de costes de transacción que no facilitan la consecución de acuerdos de gobierno, ya que los costes de la contratación superan los posibles beneficios de la misma. ${ }^{35}$

En el caso de la política económica y dado su perfil crecientemente técnico, el presidente del gobierno la ha delegado en otros miembros de su ejecutivo, aun cuando en algún caso haya ejercido control directo de ciertas prioridades (Gunther, 1996), y se reserve la resolución de ciertas disputas. De ese modo, la posición dominante del ejecutivo en estas materias se centra en el Ministerio de Economía y Hacienda. ${ }^{36}$ Se trata de un superministerio con alto grado tanto de autonomía como de intervención, con mayor número de propuestas al Consejo de Ministros.

El presidente del gobierno, más que delimitar las prioridades económicas generales, delega en el Ministerio de Economía la autoridad para administrar el gasto, sin perjuicio de reservarse la resolución de ciertas disputas. ${ }^{37}$ De este modo, la praxis política se caracteriza por un Ministerio de Economía que es capaz de determinar las posibilidades de acción de otros ministerios (Heywood, 1998).

Ese amplio poder del ministerio debe entenderse en un marco institucional en el cual ni el parlamento ni los partidos políticos ni los grupos de interés tienen la capacidad de capturar totalmente la decisión político-económica. Sin embargo, sí es posible la existencia de tensiones, como en el caso de los gobiernos socialistas de la década de los ochenta, cuando las prioridades del Ministerio de Economía entraban en conflicto con la sensibilidad de buena parte del partido socialista.

Finalmente, un panorama de la reciente experiencia española resulta de interés. El presidente Adolfo Suárez se ocupaba de los asuntos de alta política y no estaba demasiado interesado en las cuestiones económicas ni presupuestarias, que correspondieron al vicepresidente para Asuntos Económicos, cargo desempeñado por Enrique Fuentes Quintana (julio 1977-febrero 1978), Fernando Abril Martorell (febrero 1978-septiembre de 1980) y Leopoldo Calvo Sotelo (septiembre 1980-marzo de 1981). Ellos fueron los encargados de presidir la Comisión Delegada de Asuntos Económicos y el presidente Suárez sólo intervenía cuando los conflictos interdepartamentales no encontraban otro espacio de resolución.

Cuando a Leopoldo Calvo Sotelo se le elegió presidente en 1981, dado su interés en lo económico-presupuestario, continuó desarrollando algunas de esas tareas personalmente, sin delegarlas.

35 En ese sentido, rasgos institucionales como la posible investidura del ejecutivo en segunda votación sin mayoría absoluta favorece la explicación de la existencia de gobiernos minoritarios en España.

36 Este ministerio, entre otras funciones, asume la de responsable del Tesoro, de la elaboración de los presupuestos del Estado, de la formación de la política fiscal, del comercio exterior y de la política de inversión. Piénsese por ejemplo que, en asuntos como la privatización del INI, el Ministerio de Economía se reservó todos los poderes mientras el conjunto del gobierno apenas fue informado (Heywood, 1998).

37 En la coordinación presupuestaria, ocupan un lugar destacado el presidente, el propio consejo de ministros y la comisión de secretarios y subsecretarios de Estado.

\section{DeSarrollo}


Con la victoria del Partido Socialista en 1982 se estableció un nuevo modelo de relación entre el presidente, Felipe González, y el encargado de elaborar esta política económica. El papel clave de ésta no lo va a desempeñar el vicepresidente del gobierno, a pesar de ser quien preside el comité de subsecretarios, sino el ministro de economía (primero Miguel Boyer, después Carlos Solchaga). Las tensiones entre las posturas de éstos y las sostenidas por el vicepresidente en nombre del partido surgieron en los años ochenta. En los noventa, con el acceso de Narcís Serra a la vicepresidencia del gobierno, las tensiones con el Ministerio de Economía (encabezado en esa época por Pedro Solbes) perdieron relevancia .

En los gobiernos de José María Aznar se dota al vicepresidente segundo y ministro de economía, Rodrigo Rato, de amplios poderes en materias económicas. En esa etapa, el esquema organizativo determinado por el presiente separó el Ministerio de Economía y el de Hacienda, estando el segundo supeditado al primero, que se correspondía con la vicepresidencia del ejecutivo.

El gobierno presidido por José Luis Rodríguez Zapatero encomendó al vicepresidente económico, Pedro Solbes, las tareas en este rubro. Al igual que en los gobiernos anteriores, la cabeza del ejecutivo cede las cuestiones de política económica a un hombre fuerte del ejecutivo con trayectoria profesional en su ámbito.

En definitiva, la estructura institucional del sistema político español concede amplios márgenes de actuación al presidente del gobierno, entre los cuales está la elaboración de la política económica. El presidente ha delegado la formación de políticas a algún otro agente con un perfil más especializado y técnico, ya fuera vicepresidente o ministro del gobierno. Para ello, el presidente está dotado de amplia discrecionalidad, concedida por la estructura de gobernanza del sistema político español.

En ese proceso, el parlamento ocupa un lugar secundario, siempre que la primera fuerza política tenga mayoría absoluta. En otro caso, ocupa un papel más relevante en materia de política económica, tal como mostró la etapa 1993-1996 de gobierno socialista y la etapa 1996-2000 de gobierno popular. En ambas, al ser necesario su apoyo, las fuerzas nacionalistas ejercieron fuerte influjo en las decisiones económicas. ${ }^{38} \mathrm{La}$ legislatura abierta en 2004 parece corroborar esos precedentes.

La estructura institucional para la elaboración de la política económica incorpora también, en los últimos tiempos, un conjunto de instituciones "no-mayoritarias" en el sentido de Majone (2001), quien incluye desde agencias sectoriales, a las cuales se delega cierto tipo de decisiones, hasta el propio banco central.

38 En Aguilera de Prat (2001) se explican ciertos rasgos de los pactos de gobernabilidad de 1993 y 1996, destacándose la importancia de los retos económicos en un escenario de búsqueda de convergencia europea.

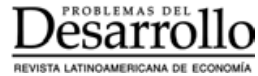


Y junto a ello no debe olvidarse la relevancia del control de la burocracia por parte del poder político (ejecutivo) para que las políticas públicas sean efectivas. ${ }^{39}$ Constatada en el plano teórico, desde un enfoque transaccional, la adecuación de la burocracia pública como forma de gobernanza para determinadas transacciones y en ciertas condiciones (Williamson, 1999), cabe situar a la burocracia española en un contexto de trayectoria histórica que no rompe durante la transición con el modelo burocrático heredado del franquismo. Ese modelo se estructuraba jerárquicamente, poseía fuerte profesionalización, estaba fragmentado en multitud de cuerpos y era dirigido por los órganos de elite. Se trataba de una burocracia que había ejercido un alto poder y cuya reforma y modernización fue gradual, llegando el Tribunal Constitucional a invalidar algún intento de reforma burocrática de trazo grueso (tal fue el caso de la Ley de Reforma de la Función Pública de 1984). Cuando se cerró el siglo xx, la administración pública española siguió ejerciendo fuerte influjo en la formación de las políticas públicas, constituyendo un agente del ejecutivo (principal) que consiguió amplia capacidad de maniobra y poderes. ${ }^{40}$ Así, la institución parlamentaria busca respaldo en un sistema burocrático unificado y coordinado, que esté controlado centralmente por los líderes políticos y que tenga una jerarquía de administración designada racionalmente.

\section{Conclusiones}

Este artículo ha presentado una radiografía de la estructura del estado español, la cual analiza los determinantes institucionales de su política económica, específicamente la tradición jurídica, el sistema parlamentario, la presencia de actores de veto, la atención de intereses públicos por parte de los partidos políticos y la estructura de jerarquía en la relación de agencia para la elaboración de la política económica. La articulación del texto se inició presentando dos reglas estructurales de los fundamentos políticos de la economía española (derecho civil, parlamentarismo), para posteriormente analizar otros rasgos de la solución institucional adoptada en España que conllevan efectos para la formación de la política económica. En ese sentido, se ha abordado la problemática de los actores de veto, capacidad de compromiso y prioridades de atención de las políticas, en el sentido de Cox y McCubbins (1999), para caracterizar, así, la fórmula española. El conjunto de determinantes institucionales implica reglas que afectan al "segundo orden de

39 Los burócratas adquieren mayor experiencia que los legisladores y poseen un poder considerable, por lo cual resultan claves las instituciones que faciliten la delegación de los legisladores en la burocracia. Entre tales instituciones, podemos apuntar tanto mecanismos ex ante que alinean los intereses de la burocracia con los de los legisladores, como el propio control de la burocracia o la adecuada asignación de recursos humanos y presupuestarios (Lupia y McCubbins, 1998).

40 Un ejemplo es que la Ley de Organización y Funcionamiento de la Administración General del Estado establece que los órganos directivos de la administración sean nombrados entre funcionarios de carrera del grupo A (Villoria, 2001).

\section{DeSarrollo}


economización", en el sentido de Williamson (2000), y establecen una estructura de gobernanza jerárquica para la elaboración de la política económica, cuestión abordada en el apartado anterior. De ese modo, el trabajo se asienta en un esquema argumental coherente que transita desde reglas estructurales (cuya modificación trasciende el juego político ordinario) hacia otras más concretas que, en buena medida, son derivadas de las restricciones impuestas por las reglas superiores (Williamson, 2000).

Entre otros aspectos, esta aproximación al análisis de la caja negra del Estado español desde la perspectiva del nuevo institucionalismo ha concluido los siguientes rasgos: $a$ ) el sistema político español concede gran poder al presidente del gobierno, quien además es jefe de su partido político, por lo cual consigue designar con amplia discrecionalidad no sólo a los integrantes del ejecutivo, sino también a los candidatos a diputados. Ello provoca la existencia de preferencias similares del ejecutivo y del legislativo; $b$ ) la elaboración de la política económica del gobierno puede ser analizada como una relación de agencia vertical común con múltiples principales dispuestos a actuar en busca de sus intereses, al estilo de lo propuesto por Dixit (1996); c) el sistema político español encierra una situación de equilibrio de autocumplimiento entre poderes (teoría de juegos), la cual permite una tendencia al presidencialismo cuando hay mayorías parlamentarias sólidas; $d$ ) los gobiernos, en un sistema como el español, son una mezcla de perfiles políticos (apoyados por el partido) y técnicos (seleccionados por el propio presidente o su entorno inmediato); e) el poder y efectividad del gobierno requiere de altos niveles de cooperación con las otras administraciones territoriales y con la propia burocracia; $f$ ) el análisis de dependencia de la senda tiende a concluir sobre la estabilidad de la concentración del poder en torno al presidente de gobierno y su ejecutivo; y $g$ ) la escasa presencia de actores de veto en la estructura gubernamental dificulta la capacidad de compromiso del gobierno español y la suple con otros mecanismos reputacionales e institucionales.

En esta radiografía se ha constatado cómo la gobernanza del Estado español favorece la decisividad de las políticas públicas, así como la atención por parte de los actores políticos, a la provisión de bienes públicos nacionales (derivado esto de un sistema de incentivos que concede el protagonismo a los partidos políticos). Este escenario dificulta la capacidad de compromiso creíble de la decisión político-económica del Estado; así, la inercia institucional y la tendencia de la senda histórica ocupan un papel de garantía alternativa para el compromiso.

Este ensayo se enmarca en una novedosa línea de trabajo en materia de economía política para el caso español, con aportaciones que deberán ser desarrolladas y perfeccionadas por análisis posteriores. Esta aproximación analítica abre una agenda que puede complementar otros enfoques y propiciar un sólido análisis institucional comparativo entre distintos países. De ese modo, avanzaremos en el conocimiento de los determinantes institucionales que sesgan la formación de la política económica.

\section{DeSarrollo}




\section{Bibliografía}

Aguilera de Prat, C.R., "Los socialistas ante los pactos de gobernabilidad de 1993 y 1996", en Revista de Estudios Políticos, núm. 111, 2001, pp. 9-43.

Andonova, V., "Property Rights and the Structure of Political Competition", presentado en la II European School for New Institutional Economics, Cargese, 2003.

, "Voting Rules, Horizontal Government, Law and Finance", presentado en la Annual Conference of the International Society for New Institutional Economics Conference, Cambridge, MIT, 2002.

Arias, X.C. y G. Caballero, "Instituciones, Costes de Transacción y Políticas Públicas: un panorama", en Revista de Economía Institucional, núm. 8, 2003, pp. 117-146.

, "The Institutional Foundations of Democratic Reforms in Spain: the Case of Financial Regulation", presentado en la Annual Conference of the International Society for New Institutional Economics, Cambridge-Mass., MIT, 2002.

Bagehot, W. (1867), The English Constitution, Cambridge, Cambridge University Press, 2001.

Barzel, Y., A Theory of the State, Cambridge, Cambridge University Press, 2002.

Bayona, A., "Federalismo y Autonomía", presentado en el International Forum on Federalism, Veracruz, 2001.

Besley, T., "Political Selection", en Journal of Economic Perspectives, vol. 19-3, 2005, pp. 43-60.

Caballero, G., "Instituciones, federalismo defensor de mercados y Estado de las Autonomías. Un análisis de segunda generación", en El Trimestre Económico, núm. 286, 2005a, pp. 283-328.

, "El Estado y la transición a la democracia en el desarrollo económico español", en Revista de Comercio Exterior, vol. 55, núm. 3, 2005b, pp. 226-241.

, "Institutional change from francoism to democracy in Spain: A Historical Institutional Analysis", presentado en Annual Meeting of the Public Choice Society, New Orleans, 2005c.

, "Instituciones e historia económica: visiones y teorías institucionales", en Revista de Economía Institucional, núm. 10, 2004, pp. 135-158.

_ - "El programa de la nueva economía institucional: lo macro, lo micro y lo político", en Ekonomiaz, núm. 50, 2002a, pp. 230-261. , "The Institutional Foundations of the Spanish Economic Miracle, 1950-2000. A New Institutionalist Approach", Warwick Research Euro-Workshop: Government and Institutions in Twentieth Century European Economic History, United Kingdom, 2002b.
—_, "La Nueva Economía Institucional", en Sistema, núm. 161, 2001, pp. 59-86.

Caballero, G. y X.C. Arias, "Una reorientación teórica de la economía política: el análisis político de costes de transacción", en Revista Española de Ciencia Política, núm. 8, 2003, pp. 131-164.

Caballero, G. y C. Kingston, "Capital social e instituciones en el proceso de cambio económico", en Ekonomiaz, núm. 59, 2005, pp. 72-93.

Coase, R.H., "The Problem of Social Cost", en Journal of Law and Economics, vol. 3, núm. 1, 1960, pp. 1-44.

- "The Nature of the Firm", en Economica, núm. 4, 1937, pp. 386-405.

Colomer, J.M., Instituciones Políticas, Ariel Ciencia Política, 2001

- La transición a la democracia: el modelo español, Barcelona, Anagrama, 1998.

Cox, G. y M.D. McCubbins, "The Institutional Determinants of Economic Policy Outcomes", presentado en la Annual Conference of the International Society for New Institutional Economics, Washington, 1999.

Denzau, A.T. y D.C. North, "Shared Mental Models: Ideologies and Institutions", en Kyklos, vol. 47, 1994, pp. 3-31.

Dixit, A.K., The Making of Economic Policy: A Transaction- Cost Politics Perspective, Cambridge, The мIт Press, 1996.

Epstein, D. y S. O'Halloran, Delegating powers. A transaction cost politics approach to policy making under separate powers, Cambridge, Cambridge University Press, 1999.

Furubotn, E.G. y R. Richter, Institutions and Economic Theory. The Contribution of the New Institutional Economics, Michigan, The University of Michigan Press, 1998.

Gunther, R., "Spanish Public Policy: from Dictactorship to Democracy", Working Paper 84, Madrid, CEACs, Instituto Juan March, 1996.

Hahn, F., "General Equilibrium Theory", en D. Bell e I. Kristol, The Crisis in Economic Theory, Nueva York, Basic Books, 1981.

Heywood, P., "Power Diffusion or Concentration? In Search of the Spanish Policy Process", en West European Politics, vol. 21, núm. 4, 1998, pp. 103-123.

Jones, M. et al., "Proffesional Politicians- Amateur Legislators: The Argentine Congress in the $20^{\text {th }}$ Century”, presentado en la Annual Conference of the International Society for New Institutional Economics, Tübingen, 2001. 
La Porta, R., "Law and Finance", en Journal of Political Economy, vol. 106, núm. 6, 1998, pp. 1113-1155.

Linz, J., "Política e intereses a lo largo de un siglo, 1880-1980", en M. Pérez Yruela y S. Giner (editores), El corporatismo en España, Barcelona, Ariel, 1988, pp. 69-112.

Lupia, A. y M. D. McCubbins, The Democratic Dilema, Cambridge, Cambidge University Press, 1998.

Majone, G., "Nonmajoritarian Institutions and the Limits of Democratic Governance: A Political Transaction-Cost Approach", en Journal of Institutional and Theoretical Economics, núm. 157, 2001, pp. 57-78.

Moe, T.M., "Political Institutions: The Neglected Side of the Story", en Journal of Law, Economics and Organization, núm. 6, 1990, pp. 213-253.

Moe, T.M. y M. Caldwell, "The Institutional Foundations of Democratic Government: A Comparison of Presidential and Parliamentary Systems", en Journal of Institutional and Theoretical Economics, vol. 150, núm. 1, 1994, pp. 171-195.

Molins, J.M. y A. Casademunt, "Pressure Groups and the Articulation of Interests", en West European Politics, vol. 21, núm. 4, 1998, pp. 124-146.

Montero, J.R., "Stablishing the Democratic Order: Electoral Behaviour in Spain", en West European Politics, vol. 21, núm. 4, 1998, pp. 53-79.

North, D.C., "La evolución histórica de las formas de gobierno", en Revista de Economía Institucional, núm. 2, 2000, pp. 133-148.

, "In Anticipation of the Marriage of Political and Economic Theory", en J.A. Alt, M. Levi y E. Ostrom, Competition and Cooperation. Conversations with Nobelists about Economics and Political Science, Russell Sage Foundation, Nueva York, 1999, pp. 314- 317.

- Institutions, Institutional Change and Economic Performance, Cambridge, Cambridge University Press, 1990a.

, "A Transaction Cost Theory of Politics". Journal of Theoretical Politics, vol. 2, núm. 4, 1990b, pp. 355-367.

North, D.C. y B.R. Weingast, "Constitutions and Commitment: the Evolution of Institutions Governing Public Choice in SeventeenthCentury England", en The Journal of Economic History, vol. 49, núm. 4, 1989, pp. 803-832.

Olson, M., Power and Prosperity, Nueva York, Basic Books, 2000.

, The Rise and Decline of Nations, New Heaven, Yale University Press, 1982.

_ L Logic of Collective Action, Harvard Universiy Press, 1965.

Persson, T.; Roland, G. y G. Tabelini, "Separation of Powers and Political Accoutability", en The
Quaterly Journal of Economics, vol. 112 (noviembre), 1997, pp. 1163-1202.

Reniu, J.M., “'Merece la pena coaligarse? La formación de gobiernos minoritarios en España, 1977- 1996", en Revista Española de Ciencia Política, núm. 5, 2001, pp. 111-142.

Sáez Lozano, J.L., "Estabilidad política y economía en la democracia española", en Revista de Estudios Políticos, núm. 110, 2000, pp. 123-138.

Shepsle, K., "The Political Economy of State Reform. Political to the Core". Annual Conference of the International Society for New Institutional Economics, Washington D. C, 1999.

_, "Discretion, Institutions and the problem of Government Commitment", en Bourdrieu, P. y J.Coleman (eds): Social Theory for a Changing Society, Boulder, Western Press, 1991.

Toboso, F. y R. Compés, "Nuevas tendencias analíticas en el ámbito de la Nueva Economía Institucional. La incorporación de los aspectos distributivos", en Trimestre Económico, núm. 280, 2003, pp. 637-671.

Tsebelis, G., "Decision Making in Political System: Veto Players in Presidentialism, Parliamentarism, Multicameralism and Multipartism", en British Journal of Political Science, núm. 25, 1995, pp. 289-325.

Vallés, J.M. y A. Bosch, Sistemas electorales y gobierno representativo, Barcelona, Ariel, 1997.

Villoria, M., "El papel de la burocracia en la transición y consolidación de la democracia española: primera aproximación", en Revista Española de Ciencia Política, vol. 1, núm. 1, 2001, pp. 97125.

Weingast, B.R., "The Economic Role of Political Institutions: Market-Preserving Federalism and Economic Development", en Journal of Law, Economics and Organization, vol. 11, núm. 1, 1995, pp. 1-31.

, "Constitutions as Governance Structures: The Political Foundations of Secure Markets", en Journal of Institutional and Theoretical Economics, vol. 149, núm. 1, 1993, pp. 286311.

Weingast, B.R. y W.J. Marshall, "The Industrial Organization of Congress; or, Why Legislatures, Like Firms, Are Not Organized as Markets", en Journal of Political Economy, núm. 96, 1988, pp. 132-163.

Williamson, O.E., "The New Institutional Economics: Taking Stock, Looking Ahead", en Journal of Economic Literature, núm. 38, 2000, pp. 595613.

, "Public versus Private Bureaucracies: A Transaction Cost Economic Perspective", en Journal of Law, Economics and Organization, vol. 15, núm. 1, 1999, pp. 307-342. 